\title{
Today's college students: Skimmers, scanners and efficiency-seekers
}

\author{
Kate Lawrence \\ Vice President of User Research, EBSCO Information Services, 10 Estes Street, Ipswich, MA 01938, \\ USA \\ E-mail: klawrence@ebsco.com
}

\begin{abstract}
This paper examines the research habits and behaviors of today's college students. With each technological evolution, students develop increasingly efficient strategies, becoming experts in time management for personal and academic purposes. With demands for their time that include school assignments, social media and 'me time', today's students are rejecting previously-held beliefs about how to conduct research and forging their own unique path towards scholarship. Starting with uncovering what one student called "the Google and Wikipedia cat and mouse game", a team of EBSCO researchers discovered that for academic research, traditional rules don't apply, and strategies for conducting research are as diverse as the students themselves.
\end{abstract}

Keywords: College students, university students, search habits, research habits, information-seeking behavior

Like other companies conducting research, each user research project at EBSCO Information Services begins with a hypothesis. On EBSCO's User Research team, we are often conducting research based on a set of assumptions held by the company, ourselves, or both.

We spend a significant amount of time studying users doing college-level research because EBSCO's products are available at the majority of college and university libraries throughout the world, and in order to make these products intuitive to this audience we need a deep understanding of these users' needs. When we study this audience, often the hypothesis we're working with is that we as a team, or we as a company, may already understand some of these user needs based on our own experience as students, our knowledge of technology, or usage statistics we may have collected.

This hypothesis is based on a number of assumptions: that our own student experience is relevant and representative, that technology innovations impact students' research habits, and that usage data alone may illuminate what students expect from our products. Our continued research on students has proved that there is no single hypothesis about college-level research habits, that today's college student population is as complex as they are diverse. At EBSCO, our study of the lives and information-seeking habits of college students isn't an occasional project; it's an ongoing research activity that continually informs the development of EBSCO's products and services.

Life has changed significantly for today's college students with the rise of digital technology. We quickly discovered that students approach their studies the same way they organize their lives: through a formula based on interest, priority and return on investment (ROI). We uncovered surprising insights about who students are most likely to consult when they encounter an obstacle in the course of their research. And we found that students aren't just seekers of knowledge but also seekers of efficiency; they are today's champion multi-taskers because their list of what they want to accomplish - in school and in life - is long. 


\section{Methodology: The importance of "zooming out"}

Studying student research habits is a more comprehensive task than simply identifying usability obstacles in a single interface. Researchers achieve greater insight when they "zoom out" to study a user's entire digital ecosystem and can identify the spectrum of user behaviors and pinpoint areas for product improvements, new services and features.

This act of zooming out is not easily accomplished by traditional research methods. Usability testing, a popular user research method, has its limitations. Test scenarios are typically written by stakeholders and test moderators and follow a prescribed order, and therefore don't necessarily reflect users' organic behavior. Going "off-script" is often not sanctioned, and does not allow for a deep exploration of user pain points with a given product or process.

We on EBSCO's User Research team have come to rely on the contextual inquiry method [1] for uncovering insights about the academic audience. Contextual inquiry is a method in which data collected by researchers includes "observed behavior of customers in the product acquisition and use environment" [2]. With its roots in anthropology and ethnography, contextual inquiry enables a wider understanding of the user's landscape than traditional user research methods because it focuses on organic tasks in within a user's natural environment.

\section{Students' prioritization of research}

By considering the dimensions and accompanying complexities of a user's life, other factors become immediately relevant. For EBSCO's student research study, the contextual inquiry method enabled researchers to understand how students prioritize their work, and we found that this task was not separate from how students prioritized their life: the critical element is efficiency. School work, employment, time with friends and family, social media time, sleep, alone time - all of these were expressed by the 22 students in the EBSCO student sample as important activities. For many participants, the morning ritual included a daily prioritization exercise of their school assignments.

This prioritization happens in three phases. First, students determine the urgency of work relative to its importance. This involves reviewing a list of assignments and their due dates; students told us that they often prioritize the work that is due the soonest.

Second, students evaluate an assignment's importance to them based on a number of possible factors, including whether the assignment is for a course in the student's major or may have an impact on their career after graduation. As one student noted, he would only "bring his B game" to an assignment for a class that fulfilled a requirement but wasn't directly related to his interests. In the third phase, students allocate a "chunk of time" to the assignment. This allocation is typically condensed; students told us repeatedly that they wait until the last $20 \%$ of the assignment period to start and finish the work.

\section{The influence of Google and Wikipedia}

Once students have prioritized work and made a commitment to start their research assignment, the most common starting point is Google, which serves as the point of triage for digital natives. Students overwhelmingly relied on Google to point them to the right answers and referred to the search engine as their "oxygen", "mother" and even "my soulmate - because Google anticipates my every need". 
One way in which Google anticipates student needs is by a comprehensive auto-complete, giving users guidance after only a few letters have been typed in a search box. Additionally, Google offers answers on the results page in the form of its knowledge graph panels, launched in 2012. Google's intention with the knowledge graph panels was to "begin spitting out more than a list of blue Web links, to present more facts and direct answers to queries at the top of the search-results page" [3]. This intention is deeply appreciate by students - one student said explicitly that she values Google because it is "more than just a list of links".

One feature of the Google results that students have come to reply upon is the appearance of a Wikipedia result at the top on the first page, typically the first result. While students acknowledge educators' guidance to not trust Wikipedia, the site is still considered a valuable resource and students feel that using it as a reference is tacitly permitted. Student participants in EBSCO's study shared many stories of teachers and professors advising against the use of Wikipedia. "It's like a cat and mouse game wink, wink", said one college nursing student in the EBSCO study, "they [professors] tell us not to use Wikipedia, and we agree not to, even though we know - and they know - we will anyway".

What students reported as the single most important aspect of Wikipedia was the first paragraph, the topic overview written in "layman's terms". When assigned a topic, often the professor will also guide students by suggesting sources in the form of databases, books, other resources. While Wikipedia is never on the instructor's list of suggested sources, the students told us they start with Google and then go to Wikipedia for the purpose of gaining an overview of their topic that can give them the context they need to then proceed to the resources recommended by their professor. Wikipedia allows students the opportunity to grasp their topic more fully before proceeding to the recommended scholarly resources.

The critical lessons to be derived from this deeply-ingrained student habit cycle of Google and Wikipedia are about context and confidence. Students want definition and explanation of their research topics before starting deep, analytical work. They want a mastery of the basic tenets of their topic because the steps that follow - seeking scholarly sources, discerning among resources, analysis and writing, perhaps even seeking help from a peer or a librarian - require both knowledge of their topic and self-confidence.

It is the notion of confidence while conducting research that is the second lesson to be learned from the Google-Wikipedia habit. Students reported feeling anxious about starting research: they didn't know how to start, their topic wasn't clear, their search terms or keywords weren't immediately obvious. By starting in Google - with its powerful auto-complete and its results page of answers, not just links students have an opportunity to gain confidence. And if they made a mistake, Google knew their habits well enough to help correct it, or another search was only a click away. Seeing Wikipedia as a top result on Google was familiar territory; students were able to click into another known site to get deeper information on their topic. Once in Wikipedia, the first paragraph gave the topic overview in a language that was clear and uncomplicated. After completing this Google and Wikipedia cycle, the student has gained sufficient confidence to proceed to scholarly channels.

\section{Search results: The critical juncture}

Once the student builds the foundation of their research using Google and Wikipedia, they will typically proceed to scholarly databases and sources as recommended by their professors. When they move from these open-web resources to more scholarly ones, they bring with them the expectation that search 
results will be "more than just a list of links". The search results page, once a portal to detailed information about a product or service, has become an entity in its own right; the singular page that matters most.

Search results is the page where students decide "is this tool for me?" and "will I stay or will I go?" and so confidence again plays an important role in a user's experience of that page. The primary cues that inform that decision to stay include seeing their search term repeated in the body of the page, the accessibility of language and the availability of familiar metadata that allows them to make a determination of relevancy. The binary decision-making mode that students operate in on the results page means that the absence of meaningful metadata on the search results page forces them to click deeper into the detailed record page to make this decision, a process they reported as annoying and time-consuming. It's important to note that more metadata doesn't necessarily mean better decision-making on search results - students are looking for proxies for what they've come to rely on to make decisions on Google search results.

It is on the search results page when students start collecting their sources for their assignment. They do this by scanning the page, evaluating titles for their keywords, and then selectively skimming abstracts. When an item appears relevant, students open it in a new browser tab. Students indicated that they may have "more than 30" tabs open at a time, and that their laptop stays on for the duration of the time they work on that assignment. Over time, when the 'seeking' phase of the research turns into the 'weeding' phase, students will go back to the collection of open tabs and evaluate the items they had previously selected for a second round of consideration. This round of consideration merits a deeper form of scanning but still not a deep or thorough read of the item, as its relevance and importance to the student's assignment hasn't been established yet.

The notion that true, deep reading is not occurring on the initial, cursory evaluation of the search results page - or even perhaps the secondary viewing when selected items are reviewed in the open tabs - is not unique to the student research process. This is a phenomenon of what neuroscientists call the evolving digital brain, and is a coping mechanism for the massive volume of content available online. Cognitive Neuroscientist Dr. Maryanne Wolf questions whether users realize that the ease of accessing information online sends the message that deep topic research isn't necessary. "From a pedagogical perspective, when information seems so complete, what motivation is there to go beneath and beyond it? From a cognitive neuroscience perspective, the digital culture's reinforcement of rapid attentional shifts and multiple sources of distraction can short-circuit the development of the slower, more cognitively demanding comprehension processes that go into the formation of deep reading and deep thinking" [4].

Our student participants consistently referred to their reading behavior as "skimming" or "scanning", and reported they'd learned these efficiency techniques as preparation for the reading comprehension sections of standardized tests like the SAT. As with many other behaviors we witnessed during the course of this study, student found these strategies efficient, and adopted them into their research process.

Like deep reading, deep exploration of search results does not play a role in our participants' research process. Participants indicated they rarely if ever proceed beyond the initial page of results in Google or other search tools, including scholarly resources. The implication for scholarly databases is a greater emphasis on tools such as Discovery, tools that bring the best and most relevant results to the top of the search results list through their complex ranking algorithms.

While conducting searches, students may encounter a research roadblock; not finding the sources they had anticipated, or needing help narrowing their search query. The students in our sample were asked who they consult as a resource when they encounter such a roadblock, and the answer was overwhelmingly "my peers". Students became aware very quickly of which students were considered experts in 
specific subjects, and those expert students became their 'go-to' resource for questions in that area. Students also consulted peers based on proximity. If the student is working in their dorm room, a roommate is the top-of-mind resource, followed by students on the same hall and then elsewhere in the dorm.

Students were aware of the presence and availability of librarians, but reported they were less likely to seek librarian help than the help of a peer due to convenience. Many students are writing papers in their dorm rooms late at night and accessing the virtual library from their campus residence, thus reducing their exposure to librarians for in-person reference consultations.

\section{Conclusion}

Students have diverse strategies for evaluating search results. These techniques are based on early experiences with Google and Wikipedia, and rely on initial search steps that build confidence and foundational knowledge. It is important to accept the influence of Google and Wikipedia and design products that while innovative, are rooted in the familiarity of a user's most frequent site experiences. By creating experiences that help to build students' confidence in their abilities, and providing a clear, intuitive path to the highest-quality and most relevant scholarly content, students become more likely to deem an experience efficient and adopt it into their evolving digital ecosystem.

\section{Acknowledgements}

The author would like to acknowledge the contributions of Deirdre Costello of EBSCO Information Services who served as co-researcher for the 2014 EBSCO student study referenced in this paper, and for her contributions as editor of this paper. Also, thank you to Beth Sauer of EBSCO Information Services who assisted in the literature review for this paper.

\section{References}

[1] H. Beyer and K. Holtzblatt, Contextual Design: Defining Customer-Centered Systems, Morgan Kaufmann, San Francisco, CA, 1998.

[2] C.M. Creveling, J. Slutsky and D. Antis, Product design using design for six sigma, in: Design for Six Sigma in Technology and Product Development, Prentice-Hall, Upper Saddle River, NJ, 2003, pp. 71-110.

[3] A. Efrat, Google gives search a refresh, Wall Street Journal, 12 March 2012, retrieved 09 May 2015, available at: http://www.wsj.com/article_email/SB10001424052702304459804577281842851136290-lMyQjAxMTAyMDEwNDExN DQyWj.html.

[4] M. Wolf and M. Barzillai, The importance of deep reading, Educational Leadership 66(6) (2009), 32-37. 